\title{
3D FAILURE ENVELOPE OF A SINGLE PILE IN SAND
}

\author{
Zheng $\mathbf{L i}^{1,2}$, Panagiotis KOTRONIS ${ }^{1}$ and Sandra ESCOFFIER ${ }^{2}$ \\ ${ }^{1}$ LUNAM Université, Ecole Centrale de Nantes, Université de Nantes, CNRS \\ Institut de Recherche en Génie Civil et Mécanique (GeM) \\ 1 Rue de la Noë, F-44321 Nantes, France \\ e-mail: \{zheng.li,Panagiotis.Kotronis\}@ec-nantes.fr \\ ${ }^{2}$ LUNAM Université, IFSTTAR, GERS, SV \\ F-44341 Bouguenais, France \\ e-mail: sandra.escoffier@ifsttar.fr
}

Keywords: Pile, Foundation, Capacity diagram, Sand, Failure envelope.

\begin{abstract}
Pile foundations are widely used in geotechnical and offshore engineering. When subjected to a combination of horizontal, vertical forces and bending moments, a $3 D$ failure envelope is necessary in order to evaluate the safety of the pile-soil system. We present a study on the failure envelope of a single elastic pile in sand. In order to find it in the three-dimensional space (i.e. horizontal force $H$, bending moment $M$ and vertical force $V$ ), the radial displacement method and swipe tests are numerically performed. An analytical equation providing good agreement with the $3 D$ numerical results is finally proposed.
\end{abstract}




\section{INTRODUCTION}

The failure envelope of a single elastic vertical pile in sand is numerically investigated via swipe tests and a large number of radial displacement controlled tests. The analytical equation proposed by Meyerhof [1] is validated and adopted in the H-V plane. For the H-M-V space however, a new 3D analytical failure envelope is introduced. The proposed failure envelope is useful for the development of new simplified modelling strategies for soil-structure interaction problems (e.g. macro-elements [2]) that can be applied in design engineering offices [3].

\section{NUMERICAL MODEL}

\subsection{SOIL CONSTITUTIVE LAW}

A hypoplastic constitutive law, similar to an elastic perfectly plastic Drucker-Prager model, is used to numerically reproduce the behaviour of a single pile in sand. The basic framework of the hypoplastic formulation is provided with the following equations (bold letters define hereafter tensors and vectors, the $\operatorname{dot}^{\text {“ }}$ " symbol is the derivative with respect to time and \|\| the norm of a tensor):

$$
\dot{\mathbf{T}}=\mathcal{L} \mathbf{D}+\mathbf{N}\|\mathbf{D}\|
$$

where $\dot{\mathbf{T}}$ and $\mathbf{D}$ are the stress rate and stretching rate tensors. The stiffness matrix $\mathcal{L}$ depends on the bulk modulus $K$ and the shear modulus in the elastic range $G_{\max }$ and has the following form (the Lamé coefficient $\mu=G_{\max }$ according to Hooke's law):

$$
\mathcal{L}=K \mathbf{1} \otimes \mathbf{1}+2 \mu\left[\mathbf{I}-\frac{1}{3} \mathbf{1} \otimes \mathbf{1}\right]
$$

The constitutive tensor $\mathbf{N}$ is defined following the approach proposed by Niemunis [4]:

$$
\mathbf{N}(\mathbf{T})=-y(\mathbf{T}) \mathcal{L} \mathbf{m}(\mathbf{T})
$$

where $y(\mathbf{T})$ is a scalar function that controls the variation of the nonlinear term and $\mathbf{m}(\mathbf{T})$ defines the plastic flow direction. The scalar function $0 \leq y(\mathbf{T}) \leq 1$ is chosen as a function of the current stress $q(\mathbf{T})=\sqrt{3 J_{2}}$ and a predefined limit stress $\sigma_{\mathrm{y}}(\mathbf{T})$ as follows:

$$
y(\mathbf{T})=\left(\frac{q(\mathbf{T})}{\sigma_{\mathrm{y}}(\mathbf{T})}\right)^{n_{c}}
$$

with $n_{c}$ is a constant that controls the isotropic evolution of $y(\mathbf{T})$ and $J_{2}$ the second invariant of the deviatoric stress tensor. Assuming a dry sand and thus a zero cohesive strength $(c=0)$, $k_{c}=0$ and the yield function reads:

$$
F=q(\mathbf{T})-M_{c} p(\mathbf{T})=0
$$

The plastic flow direction $\mathbf{m}(\mathbf{T})$ is defined according to the bounding surface model $[5,6,7]$ and it is given by Eq. 6:

$$
\mathbf{m}(\mathbf{T})=\frac{\partial G / \partial \mathbf{T}}{\|\partial G / \partial \mathbf{T}\|}
$$




\subsection{CALIBRATION AND VALIDATION OF THE SOIL CONSTITUTIVE LAW FOR FONTAINEBLEAU SAND}

The soil constitutive law is calibrated and validated using experimental data on dry Fontainebleau sand. The homogeneous sand has a mid-particle diameter $D_{50}$ around $0.206 \mathrm{~mm}$, a density, $\rho_{s}=2.65 \mathrm{~g} / \mathrm{cm}^{3}$ and a minimum and maximum void ratio $e_{\min }=0.510$ and $e_{\max }=0.882$, respectively [8]. The main parameters of the soil model are summarized in Table. 1.

\begin{tabular}{ccccc}
\hline & $e$ & $n_{c}$ & $\phi_{c}$ & $\psi$ \\
\hline Dense sand & 0.577 & 0.4 & $33^{\circ}$ & $9^{\circ}$ \\
\hline
\end{tabular}

Table 1: Model parameters used in the simulation of drained triaxial tests

Comparisons with triaxial tests for dense are shown in Fig. 1. Different confining pressures are considered $(50 \mathrm{kPa}, 100 \mathrm{kPa}$ and $200 \mathrm{kPa})$.

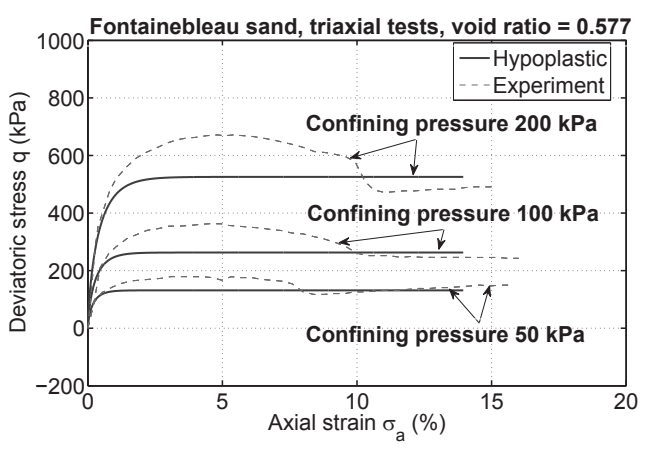

(a)

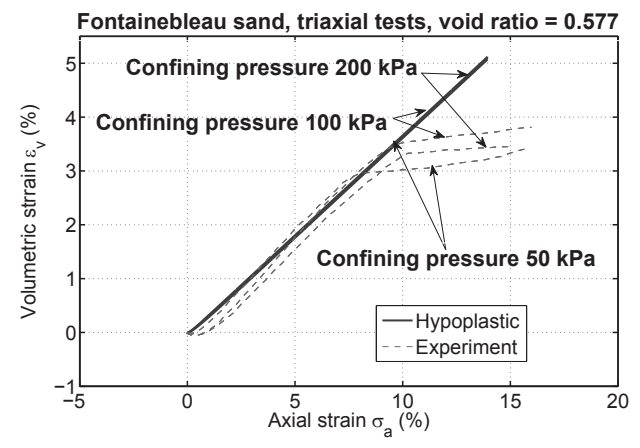

(b)

Figure 1: Triaxial compression tests on dense Fontainebleau sand, simulation vs. experiments, [9]

\subsection{FINITE ELEMENT MESH AND BOUNDARY CONDITIONS}

A numerical model of a single vertical pile in soil is carried out using the finite element code ABAQUS standard [10]. The contact behavior between the pile and the soil is considered using a friction coefficient $\mu=\tan \left(\phi_{c}\right)=0.65$ related to the critical friction angle $\phi_{c}=33^{\circ}$ of the soil. Nodal displacements are fixed in the X, Y and Z directions at the base of the finite element mesh. The displacements at the other lateral boundaries are blocked in the normal directions (see Fig. 2). 


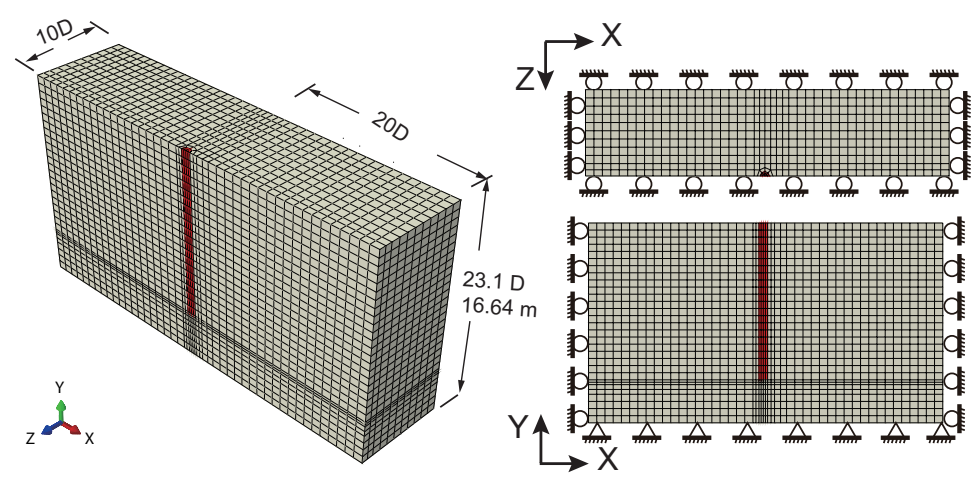

Figure 2: Finite element model for a single vertical pile in soil

\section{NUMERICAL STUDY OF THE 3D FAILURE ENVELOPE}

\subsection{PARAMETERS OF THE FINITE ELEMENT MODEL}

In the finite element model, the pile has a length of $13 \mathrm{~m}$, a diameter of $0.72 \mathrm{~m}$, a slenderness ratio of 18 and the pile head is considered on the ground surface level. Poulos and Davis [11] proposed a method to classify piles in different categories based on a flexibility factor. According to this method, the pile is classified as flexible.

\subsection{D NUMERICAL FAILURE ENVELOPE}

In order to numerically reproduce the 3D failure envelope, the radial displacement test proposed by Gottardi et al. [12] is adopted. The sign conventions for the pile head loads (horizontal force, vertical force and bending moment) are presented in Fig. 3.

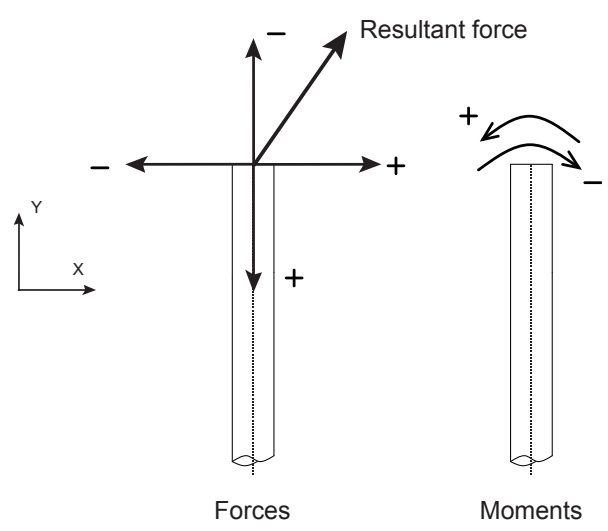

Figure 3: Sign conventions for the pile head loadings

\subsubsection{NUMERICAL FAILURE ENVELOPE IN THE H-V PLANE}

To investigate the form of the failure surface in the $\mathrm{H}-\mathrm{V}$ plane, free pile head conditions $(\mathrm{M}=0)$ are considered. A displacement is applied on the top of the pile head (that can rotate freely) in a certain direction $\delta$. The angle of the displacement $\delta$ varies from $0 \sim 360^{\circ}$ to scan the failure surface in all directions. The final strength is chosen as the point where numerical calculation diverges. By connecting the values at the ends of the different load paths the complete failure surface is thus obtained. Examples of load paths in the $\mathrm{H}-\mathrm{V}$ plane from the numerical 
radial displacement tests are shown in Fig. 5(a). Numerical swipe tests are also performed in H-V plane, Fig. 5(b) and for more complex loads in Fig. 5(c). A large number (around 500) of numerical radial displacement tests are performed and the ultimate strength (or failure locus) of each test is plotted in Fig. 5(d).

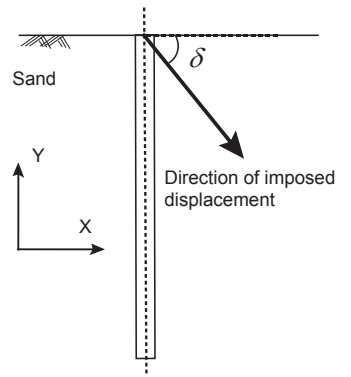

Figure 4: Radial displacements tests in the $\mathrm{H}-\mathrm{V}$ plane

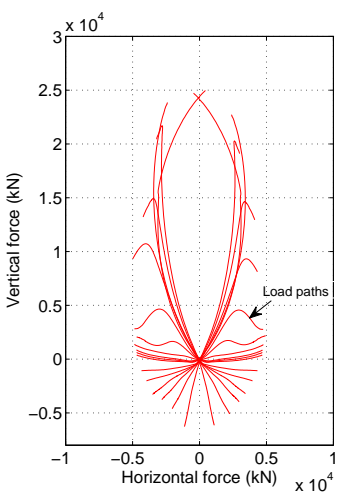

(a)

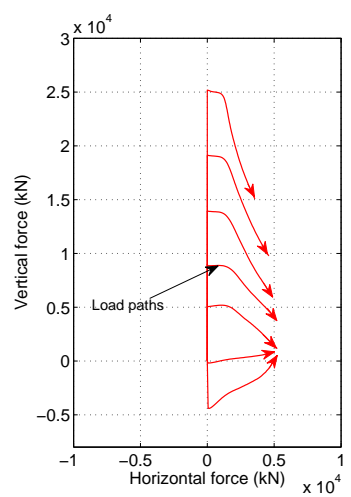

(b)

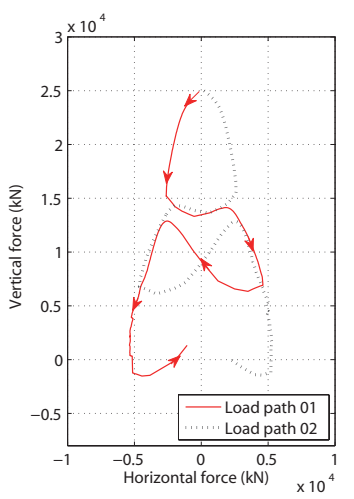

(c)

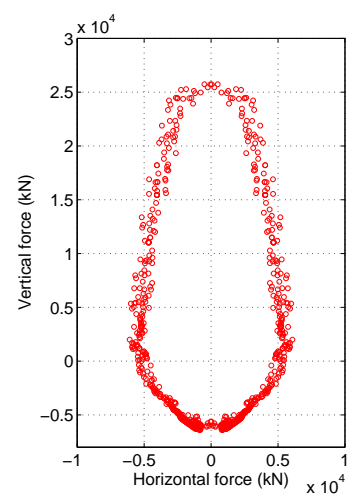

(d)

Figure 5: Selected load paths from numerical radial displacement tests (a), load paths from numerical swipe tests (b), numerical swipe tests with more complex load paths (c) and complete results from numerical radial displacement test (d), in $\mathrm{H}-\mathrm{V}$ plane $(\mathrm{M}=0)$, [9].

\subsubsection{NUMERICAL FAILURE ENVELOPE IN THE H-M PLANE}

The failure envelope is hereafter investigated in the $\mathrm{H}-\mathrm{M}$ plane and for different vertical loading levels. First, the pile is loaded until a certain vertical force. Then, radial displacement loadings are applied considering a constant ratio between the combined rotation-displacements increments. Similar to the H-V plane, load paths in the H-M plane start from the origin and stop at the failure envelope, see Fig. 6(a). Results of the numerical radial displacement tests are provided in Fig. 6(b). 


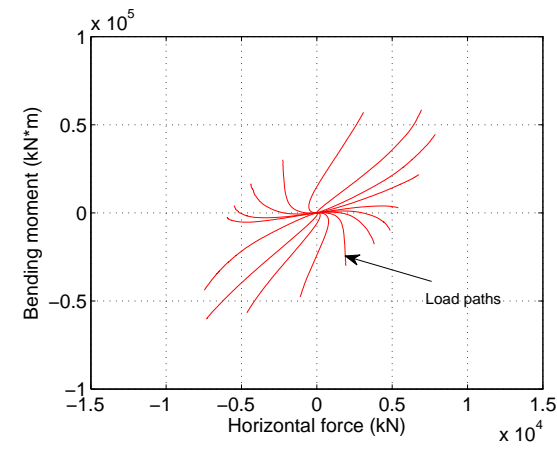

(a)

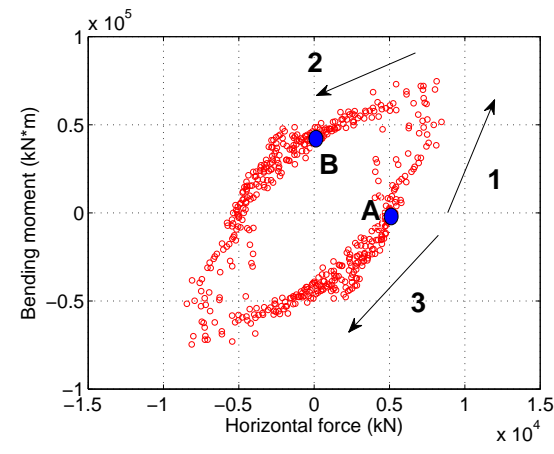

(b)

Figure 6: (a) Load paths (b) numerical radial displacement tests in the H-M plane corresponding to V=0, [9]

\subsubsection{NUMERICAL FAILURE ENVELOPE IN THE H-M-V 3D SPACE}

By combining the results in the H-V plane and in the H-M plane for different vertical load levels, the complete failure envelope is plotted in Fig. 7.

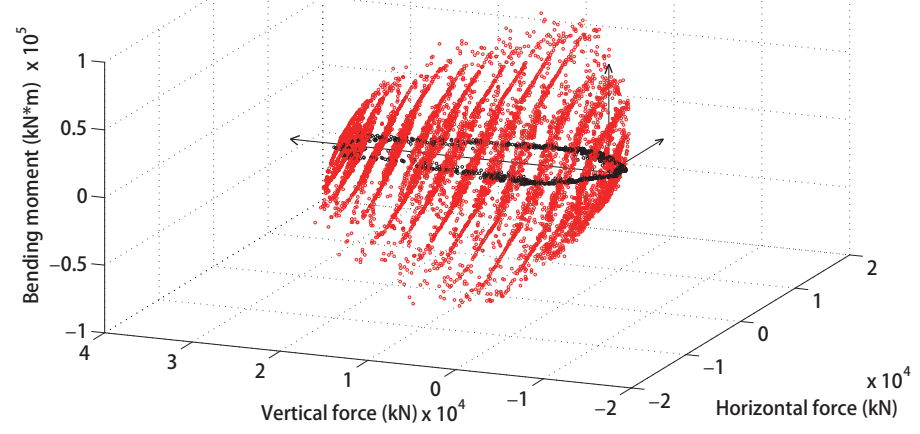

Figure 7: Numerical failure envelope in the H-M-V 3D space, [9]

From the numerical radial tests in Fig. 7 the horizontal bearing capacity ( $V=0$ and $M=0$ ) is estimated at $H_{0}=5000 \mathrm{kN}$, the vertical compression bearing capacity $(\mathrm{H}=0$ and $\mathrm{M}=0)$ $V_{c 0}=25000 \mathrm{kN}$, the vertical tension bearing capacity $(\mathrm{H}=0$ and $\mathrm{M}=0) V_{t 0}=5100 \mathrm{kN}$ and the ultimate bending resistance $(\mathrm{H}=0$ and $\mathrm{V}=0) M_{0}=0.42 \times 10^{5} \mathrm{kN} \cdot \mathrm{m}$.

\subsection{ANALYTICAL EQUATIONS}

\subsubsection{ANALYTICAL EQUATION FOR THE FAILURE ENVELOPE IN THE H-V PLANE}

Meyerhof and Ranjan [1] proposed a semi-empirical formula to evaluate the interaction between the horizontal and vertical forces that reads:

$$
\left(\frac{H}{H_{0}}\right)^{2}+\left(\frac{V}{V_{0}}\right)^{2}=1
$$

where $H_{0}$ and $V_{0}$ are the horizontal and vertical bearing capacities of the pile. Eq. (7) can be written in a normalized form as follows:

$$
f=m^{2}+v^{2}-1
$$


where $m=H / H_{0}$ and $v=V / V_{c 0}$ in compression or $v=V / V_{t 0}$ in tension. $m$ and $v$ are dimensionless quantities. The comparison of the semi-empirical Eq. (8) with the numerical results is shown in Fig. 8 (a) and (b). The agreement is satisfactory although some discrepancies are identified in the tension part (dash line).

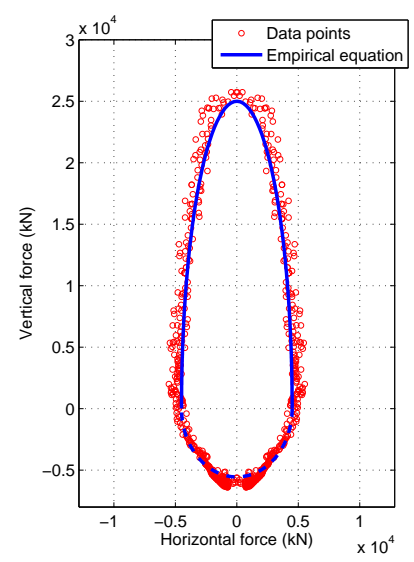

(a)

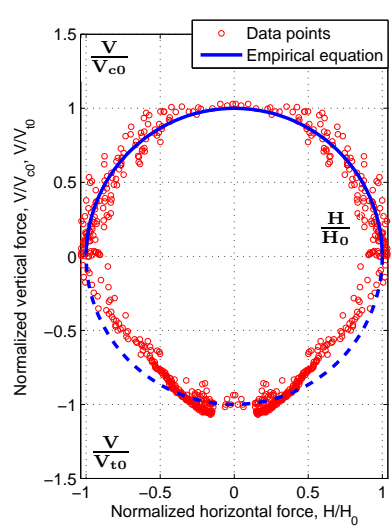

(b)

Figure 8: Comparison of Eq. (8) with the numerical results (a) in the H-V plane and (b) in the normalized $\frac{H}{H_{0}}-\frac{V}{V_{c 0}}$ $-\frac{V}{V_{t 0}}$ space, [9]

\subsubsection{ANALYTICAL EQUATION FOR THE FAILURE ENVELOPE IN THE H-M-V 3D SPACE}

As shown in section 3.2.2, the failure envelope in the $\mathrm{H}-\mathrm{M}$ plane has an inclined elliptical shape. Inspired from the work of Gottardi et al. [12], a similar equation is proposed hereafter for a single pile in sand:

$$
f=\alpha m^{2}+\xi n^{2}-\beta m n-\rho(v)=0
$$

where $m=H / H_{0}$ the normalized horizontal force, $n=M / M_{0}$ the normalized bending moment and $v=V / V_{c 0}$ or $v=V / V_{t 0}$ the normalized vertical force (dependent on the sign of the vertical load). $\alpha, \xi, \beta$ and $\rho$ are constants that control the shape of the ellipse. The parameters are first fitted using the normalized numerical data in the H-M plane at zero vertical force. They are found equal to $\alpha=1.0, \xi=1.0, \beta=1.5$ and $\rho=1.0$, Eq. (9) thus becomes:

$$
f=1.0 m^{2}+1.0 n^{2}-1.5 m n-1.0=0
$$

The fitted curves are plotted in Fig. 9 (a) and (b) and show a good agreement with the numerical data both in the $\mathrm{H}-\mathrm{M}$ and in the normalized $H / H_{0}-M / M_{0}$ plane. 


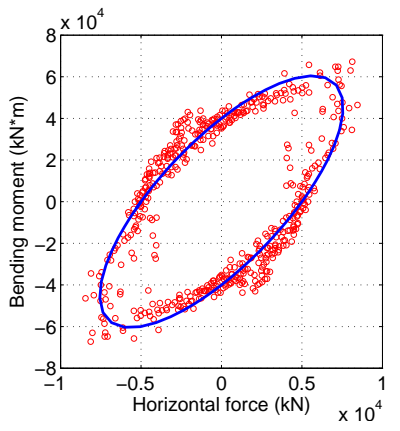

(a)

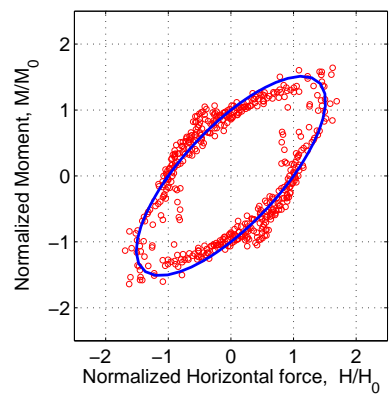

(b)

Figure 9: Comparison of Eq. (10) with the numerical results (a) in the H-M plane and (b) in the normalized $\frac{H}{H_{0}}$ $\frac{M}{M_{0}}$ plane, [9]

The vertical load influences the size of the elliptical cross-sections but not their inclinations. In order to introduce this behaviour, it is proposed hereafter to link the parameter $\rho$ in Eq. (9) and Eq. (10) with the vertical load as follows:

$$
f=1.0 m^{2}+1.0 n^{2}-1.5 m n-\left(1-v^{2}\right)=0
$$

The 3D failure envelope for a single vertical pile in sand defined by Eq. (11) is plotted in Fig. 10 together with all the numerical data points.

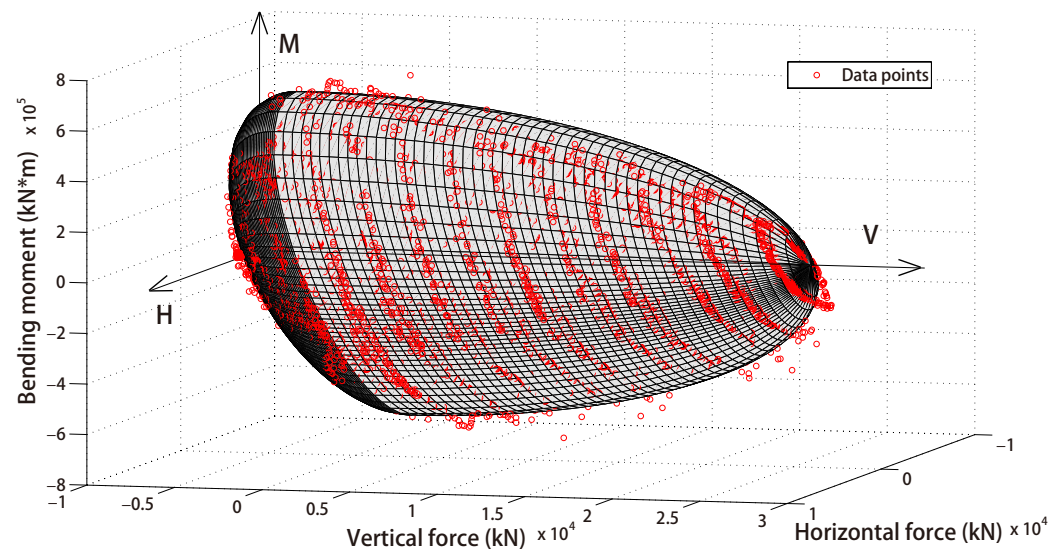

Figure 10: 3D failure envelope for a single vertical pile in sand: yield surface provided by Eq. (11) Vs. numerical data points, [9]

\section{CONCLUSIONS}

This paper presents a numerical study on the 3D failure envelope of a single elastic pile in sand and analytical equations are proposed. The key parameters for the analytical equations are relatively easy to determine either experimentally or numerically making the above equations useful for engineering design offices. More details on this work can be found in [9], [13] and [14]. 


\section{REFERENCES}

[1] G. G. Meyerhof and G. Ranjan. The bearing capacity of rigid piles under inclined loads in sand. I: Vertical piles. Canadian Geotechnical Journal, 9(4):430-446., 1972.

[2] S. Grange, P. Kotronis, and J. Mazars. A macro-element to simulate 3D soil-structure interaction considering plasticity and uplift. International Journal of Solids and Structures, 46(20):3651 - 3663, 2009.

[3] S. Grange, L. Botrugno, P. Kotronis, and C. Tamagnini. The effects of soil-structure interaction on a reinforced concrete viaduct. Earthquake Engineering and Structural Dynamics, 40(1):93-105, 2011.

[4] Andrzej Niemunis. Extended hypoplastic models Dissertation submitted for habilitation. Habilitation thesis, Ruhr-University, Bochum, 2002.

[5] Y. F. Dafalias. Bounding surface plasticity. I: Mathematical foundation and hypoplasticity. Journal of Engineering Mechanics, 112(9):966-987, 1986.

[6] Y.F. Dafalias and L.R. Herrmann. Bounding surface formulation of plasticity. John Wiley and Sons, Ltd., 1982.

[7] J. P. Bardet. Bounding surface plasticity model for sands. Journal of engineering mechanics, 112(11):1198-1217., 1986.

[8] I. Andria-Ntoanina, J. Canou, and J. C. Dupla. Caractérisation mécanique du sable de Fontainebleau NE34 à lappareil triaxial sous cisaillement monotone. Technical report, Laboratoire Navier - Géotechnique (CERMES, ENPC/LCPC), 2010.

[9] Z. Li, P. Kotronis, and S. Escoffier. Numerical study of the 3D failure envelope of a single pile in sand. Computers and Geotechnics, 62:11-26, 2014.

[10] Abaqus/Standard. Abaqus 6.10 Documentation (SIMULIA Abaqus 6.10). Dassault Systèmes, 2010.

[11] H. G. Poulos and E. H. Davis. Pile foundation analysis and design. John Wiley and Sons, Inc., New York, 1980.

[12] G Gottardi, G.T. Houlsby, and R. Butterfield. Plastic response of circular footings on sand under general planar loading. Géotechnique, 49(4):453-469, 1999.

[13] Z. Li, S. Escoffier, and P. Kotronis. Using centrifuge tests data to identify the dynamic soil properties: application to Fontainebleau sand. Soil Dynamics and Earthquake Engineering, 52:77-87, September 2013.

[14] Z. Li, P. Kotronis, S. Escoffier, and C. Tamagnini. A hypoplastic macroelement for single vertical piles in sand subject to threedimensional loading conditions. Earthquake Engineering and Structural Dynamics (submitted), 2015. 